ESCRITAS Vol. 9 n. 2 (2017) ISSN 2238-7188 p. 145-167

\title{
EMPODERAMENTO E EDUCAÇÃO NA LUTA PELOS DIREITOS DA MULHER NO BRASIL
}

\author{
EMPOWERMENT AND EDUCATION IN THE STRUGGLE FOR \\ WOMEN'S RIGHTS IN BRAZIL
}

Lorena de Barros Teixeira Sousa ${ }^{1}$

Cristiane Roque de Almeida ${ }^{2}$

\begin{abstract}
RESUMO: A violência contra a mulher figura como opressão mais resistente no tempo e no espaço. Tal opressão se verifica estrutural, atingindo, de alguma maneira, todas as mulheres. Nesse sentido, neste artigo, a partir de um resgate histórico da submissão da mulher pelo homem, apontamos as leis que marcaram os direitos das mulheres, conquistados, sobretudo, pelas lutas feministas. A partir de uma perspectiva histórica e descritiva, com uma dimensão também explicativa, mostramos que, apesar dos direitos conquistados, a mesma legislação que os garantiu, utiliza-os como instrumentos que formalizam a diferença dos sexos como, por exemplo, a diferença salarial ou mesmo o acesso ao trabalho formal entre mulheres e homens.
\end{abstract}

PALAVRAS-CHAVE: Direitos da mulher; Feminismo; Violência de gênero.

ABSTRACT: Violence against women is seen as the most resistant oppression in time and space. Such oppression is found to be structural, affecting all women in some way. In this sense, in this article, from a historical rescue of the submission of women by man, we point out the laws that marked the conquered rights of women above all, by feminist struggles. From a historical and descriptive perspective with an explanatory dimension, we show that despite the rights won, the same legislation that guaranteed them uses them as instruments that formalize the difference of the sexes, such as the wage difference or the access to formal work between women and men.

KEY-WORDS: Women's rights; Feminism; Gender violence.

\footnotetext{
${ }^{1}$ Feminista e Bacharela em Direito pela Universidade Federal do Tocantins - UFT. E-mail: lorenabarros.ts@gmail.com

${ }^{2}$ Mestre em Sociologia e graduada em Ciências Sociais pela Universidade Federal de Goiás - UFG. Docente do ${ }^{2}$ Mestre em Sociologia e graduada em Ciências Sociais pela Universidade Federal de Goiás - UFG. Docente do curso de Direito da Universidade Federal do Tocantins - UFT. Coordenadora do Programa de extensão Centro Regional de Referência sobre drogas - CRR/UFT/Centro-sul. E-mail: crisroque@uft.edu.br
} 


\section{INTRODUÇÃO}

Existem sujeitos oprimidos que se negam a deixar sua história se diluir no tempo, contradizendo os lócus em que foram engessados, marcando os espaços com suas ações. A isto denomina-se movimento. Tal é o caso dos movimentos feministas, por exemplo, que reuniram diferentes mulheres (e suas diferentes demandas), nos seus respectivos espaço e tempo, em luta por seus direitos, mas que, principalmente, registraram as mulheres na história.

Por feminismo entendemos o movimento que busca tanto a promoção da igualdade entre mulheres e homens, quanto pretende organizar as mulheres e suas demandas específicas, a fim de que consigam se emancipar deste sistema patriarcal que as coloca em situação de submissão nos aspectos públicos e privados da vida. Tal prática, contudo, somente se vislumbra libertadora, quando alicerçada pelas teorias feministas, que compreendem as mulheres nas suas diversas especificidades, e que podemos verificar em recortes como gênero, classe e raça.

\section{BREVE HISTÓRIA DA LUTA PELOS DIREITOS DA MULHER}

Somente entendemos o presente momento - como nos organizamos em sociedade, assim como as instituições e os sistemas que nos regem -, bem como idealizamos o futuro, quando conhecemos a História, a nossa história, ensinava Heródoto. Das diversas maneiras que existem para registrar a História, a história escrita, por exemplo, é a mais comum e importante, no que diz respeito ao espaço em que ocorrem os eventos e ao tempo em que se inserem.

Às mulheres tal registro foi negado por muito tempo. Não se sabe muita coisa sobre nós: nossas conquistas, derrotas, inimigos, nossos rituais, nosso corpo, etc. Aos poucos ${ }^{3}$ se constata que a história como é conhecida, foi contada por homens brancos da elite dominante que se colocaram (e se colocam) como protagonistas de tudo o que aconteceu (e acontece) no mundo - a mulher nunca foi Sujeito na História; quando se sabe que em verdade,

\footnotetext{
${ }^{3}$ Será vislumbrado no decorrer deste artigo, dadas as inúmeras autoras que pesquisaram e escrevem sobre a história da mulher, bem como suas conquistas no decorrer da história da humanidade e do início das opressões, contadas pelas próprias mulheres.
} 
são estes os grandes opressores da história da humanidade, os quais submeteram as mulheres aos seus interesses políticos e econômicos para dominação e afirmação de seu poder - e não os heróis.

No entanto, é preciso destacar que tal submissão nunca foi aceita pelas mulheres, uma vez que foram elas guerreiras, parteiras, curandeiras, cientistas, escritoras, estudiosas, revolucionárias, etc., apesar de a sociedade patriarcal lhes dizer que seu lugar era em casa, a cuidar dos filhos e do marido. Tínhamos poucas opções para nossa existência material.

O que se depreende disso é que, para manter o estereótipo feminino de submissão, os homens usaram (e usam, como veremos) a violência, uma vez que foi por eles implantada em nosso subconsciente a fragilidade, pois acreditaram que dessa forma não nos rebelaríamos contra eles. Fomos e ainda somos submissas, mas sempre subversivas.

Tais opressões sempre foram (e serão) motivo de revolta para as mulheres, ainda que silenciada pela história patriarcal. Há, sobretudo, uma incessante vontade e força das mulheres em se colocarem na história - disso se verifica que tudo o que nos foi conquistado, se deve às muitas lutas. Nos importa saber, para a construção de uma sociedade igualitária e livre das opressões, quais os avanços e os entraves que perseguem tais lutas.

Todas as citações referenciadas neste artigo dizem respeito à construção desta história. Desde à subordinação ao lar, o genocídio de mulheres instaurado no período denominado caça às bruxas, perpassando pelos "labirintos" insalubres da era industrial período que atribuiu às mulheres condições sub-humanas de trabalho.

Sobrevivendo a todos esses momentos de relevância histórica, contudo, está o Feminicídio - crime tipificado somente em 2015 na legislação penal brasileira - e que retrata uma verdadeira chacina de mulheres (sustentada pelo Estado e, muitas vezes pela Igreja) como maneira de aniquilar seu poder na sociedade, durante muito tempo na história.

Dentro do processo histórico de evolução da humanidade, a mulher nunca foi protagonista - raramente o era da sua própria história. Cecília Sardenberg e Ana Alice Costa defendem que "A subordinação da mulher na sociedade, além de se manifestar como fenômeno milenar e universal, também figura como a primeira forma de opressão [...]" (1991, p. 81). Resta-nos entender como e em que momento da história, permitiu-se que o gênero masculino predominasse. 
Segundo Engels nem sempre a sociedade se curvou ao patriarcado ${ }^{4}$. Existiu uma época em que uma criança tinha vários pais e várias mães, de modo que cada mulher pertencia igualmente a todos os homens da tribo, e cada homem pertencia a todas as mulheres - " [...] o que Bachofen chamou de matrimônio por grupos" (ENGELS, 1984, p. 36). Para o autor, em se tratando de mamíferos, podemos encontrar todas as formas de manifestações sexuais: a promiscuidade, a união por grupos, a poligamia, a monogamia; mas a poliandria, pondera, somente os humanos podem alcançar, assim ele explica "[...] o matrimônio por grupos, a forma de casamento em que grupos inteiros de homens e grupos inteiros de mulheres pertencem-se mutuamente, deixando bem pouca margem para os ciúmes" (ENGELS, 1984, p. 36).

Para Engels (1984), nas sociedades primitivas, as mulheres tinham a mesma importância que os homens para a manutenção do grupo, desempenhavam um papel de igualdade e, como não havia propriedade privada, os bens materiais eram comuns a todas as pessoas. Dizia-se que a sociedade era matriarcal, pois a descendência só podia ser vislumbrada pela linha feminina, prevalecendo assim o direito materno.

O termo matriarcado deriva, respectivamente, do latim e do grego, onde mater faz referência à mãe e archein (arca) a governar, reinar. Sendo assim, a sociedade matriarcal é o tipo de sociedade onde o poder é exercido pelas mulheres, em especial pelas mães, visto que, o fato de dar à luz conferiria à mulher o estatuto mais elevado da hierarquia familiar. Isso não significa, contudo, que a mulher ocupava um lugar de liderança. Ana Alice Costa, professora doutora do Núcleo de Estudos Interdisciplinares sobre Mulheres, Gênero e Feminismo (NEIM) da UFBA (in memorian), afirma que "[...] a única forma que mais se aproxima do matriarcado é, realmente, a iroquesa estudada por Morgan [...]” (1998, p. 22), mas que não há registros de famílias em que a mulher exercesse o poder, no artigo "As donas do poder: mulher e política na Bahia" para a Revista do NEIM.

Antes de terem estereotipadas suas condições biológicas para o esforço físico estereótipos que subsistem no tempo e espaço, tanto que habita no subconsciente feminino o arquétipo da fraqueza, que nos faz acreditar que precisamos da proteção de um macho para viver/sobreviver -, há relatos de que foram as mulheres tão guerreiras quanto os homens nas defesas contra inimigos comuns, na caça, etc. Simone de Beauvoir conta que "[...] na luta contra o mundo hostil as servidões da reprodução representavam para elas um terrível

\footnotetext{
${ }^{4}$ De acordo com Saffioti, por patriarcado entendemos "[...] um conjunto de relações sociais que tem uma base material [...]. Patriarcado é pois, o sistema masculino de opressão das mulheres” $(2004$, p. 53).
} 
handcap: conta-se que as amazonas mutilavam os seios, o que significava que pelo menos durante o período de sua vida guerreira, recusavam a maternidade" (1970, p. 82).

Não obstante, as mulheres se viram preteridas por sua condição biológica da maternidade. Como a natureza não lhes assegurava a esterilidade, as mulheres ficavam a mercê das repetidas maternidades, que diminuíam sua capacidade para o trabalho e lhes condenavam a longos períodos de "impotência", período este que consome das mulheres grande parte de tempo e força. E assim maternidade passou a ser sinônimo de fragilidade.

As primeiras pessoas a se organizarem em sociedade (e não eram muitas) lutaram penosamente para sobreviver, em vista de que eram poucos os recursos e instrumentos para tal, a ponto de, em determinado momento da história, ter mais pessoas nascendo que recursos para suprir suas necessidades. Segundo Beauvoir: "Nasciam crianças demais em relação aos recursos da coletividade; a fecundidade absurda da mulher impedia- a de participar ativamente na ampliação desses recursos, ao passo que criava indefinidamente novas necessidades" (1970, p. 82). Essa fecundidade "incontrolável” da mulher fazia com que a capacidade de organização e produção estivesse, assim, com o macho. A partir daí, para a perpetuação da espécie, defendia-se que o equilíbrio da produção e da reprodução era assegurado pelo homem (BEAUVOIR, 1970).

A gravidez e o aleitamento, por exemplo, não eram vistos como atividade, mas como funções naturais, fazendo com que não houvesse questionamento sobre essa obrigação e, consequentemente, que a mulher suportasse passivamente esse fardo biológico. Ademais, o trabalho doméstico se aproveita desse cenário de repetição para se apropriar na mulher, pois só ele parecia conciliável com a maternidade.

É mister entender que parte daquele equilíbrio somente era alcançado pelo grande número de infanticídios entre os povos nômades, e os recém-nascidos que não eram assassinados, morriam pela falta de higiene. Isto porque, para os grupos primitivos, os filhos eram vistos como incumbência, e não como riqueza. Como não possuíam território enquanto grupo, nem individualmente, não tinham preocupação de se manter. Ademais, o homem era diferente, todo e qualquer instrumento que ele inventava, se tornava um objeto de dominação sobre o mundo, fosse ele um simples bastão que lhe permitia tirar um fruto de uma árvore (BEAUVOIR, 1970). Assim, "Nessa ação, experimenta seu poder: põe objetivos, projeta caminhos em direção a eles, realiza-se como existente. Para manter, cria; supera o presente, abre o futuro. Eis porque as expedições de caça e pesca assumem um caráter sagrado" (BEAUVOIR, 1970, p. 84). 
Sobre isso, Beauvoir conta que, o macho ${ }^{5}$ acolhia suas vitórias com sentimento de festividade, divinizando qualquer objeto ou situação que o representasse, orgulho que ele "[...] manifesta ainda hoje quando constrói uma barragem, um arranha-céu, uma pilha atômica" (1970, p. 84).

Com o processo de evolução das sociedades primitivas, quando passou a produzir alimentos em larga escala, o homem sentiu a necessidade de criar a propriedade como forma de proteção de seus bens materiais. Porém, na forma como se organizavam as primeiras famílias, não tinha o homem a quem destinar sua herança, por não saber com certeza quem eram seus herdeiros. A mulher, ao contrário, tinha certeza de que a criança era sua, portanto poderia destinar seus bens a seus filhos. Dessa necessidade, concluiu o homem privar a mulher de outros relacionamentos, para que tivesse certeza de que o herdeiro era seu - do homem. Houve, então, a queda do direito materno.

[...] foram os homens, desejosos de manter as prerrogativas masculinas, que inventaram essa divisão: entenderam criar um campo de domínio feminino - reinado da vida, da imanência - tão somente para nele encerrar a mulher; mas é além de toda especificação sexual que o existente procura sua justificação no movimento de sua transcendência: a própria submissão da mulher é a prova disso. (BEAUVOIR, 1970, p. 85).

O patriarcado passa a reinar, elevando os machos ao patamar dos deuses. A mulher passa a ser um objeto de pertencimento nas relações: ao nascer, ela devia obediência ao pai e, após o casamento, ao marido. Nasce então a relação monogâmica, a qual Engels explica que "[...] foi a primeira forma de família que não se baseava em condições naturais, mas econômicas, e concretamente no triunfo da propriedade privada sobre a propriedade comum primitiva, originada espontaneamente" (1984, p. 70). Destarte, a mulher estava sujeita a todo e qualquer tipo de tratamento, inclusive o violento, usado como mecanismo para legitimar o poder e dominação masculina. Segundo Engels, "O desmoronamento do direito materno foi a grande derrota histórica do sexo feminino em todo o mundo" (1984, p. 61).

Existem inúmeros relatos na mitologia grega, por exemplo, em que os deuses (como também os mortais) tinham relações de violência com mulheres, mostrando concretamente a que serviam.

\footnotetext{
5 O sentido de "macho" usado neste trabalho é o mesmo dado por Simone de Beauvoir (1970) como sendo a figura representativa do Sujeito (o Absoluto), que decide sobre o que é a mulher (o Outro).
} 
Em Homero, os vencedores aplacam seus apetites sexuais nas jovens capturadas, escolhendo os chefes para si, por turno e segundo a sua categoria, as mais formosas; e é sabido que toda a Ilíada gira em torno de uma disputa mantida entre Aquiles e Agamenon por causa de uma escrava. Junto a cada herói, mais ou menos importante, Homero fala da jovem cativa que vive em sua tenda e dorme em seu leito. Essas jovens eram, ainda, conduzidas ao país natal dos heróis, a casa conjugal, conforme Agamenon fez com Cassandra em Ésquilo. [...] Aristófanes fala de cães molossos para espantar adúlteros e, nas cidades asiáticas, para vigiar as mulheres, havia eunucos - os quais, desde os tempos de Heródoto, eram fabricados em Quios para serem comerciados, e não serviam apenas aos bárbaros, a crer-se em Wachsmuth. Em Eurípides, a mulher é designada como oikurema, isto é, algo destinado a cuidar da casa (a palavra é neutra) e, além da procriação dos filhos, não passava de criada principal para o ateniense. (ENGELS, 1984, p. 67).

Não bastasse todas essas opressões elencadas até aqui, encontrou o homem outro meio de aniquilar mulheres como forma de demonstrar seu poderio num período denominado Caça às Bruxas. Foram aproximadamente quatrocentos anos de extermínio de mulheres nos tribunais da Santa Inquisição, na Idade Média. Segundo a militante feminista Rosângela Angelin, “[...] estima-se que aproximadamente 9 milhões de pessoas foram acusadas, julgadas e mortas neste período, onde mais de $80 \%$ eram mulheres, incluindo crianças e moças que haviam "herdado este mal" (2005, online). O que se prega sobre as bruxas é que eram mulheres más e horríveis. Sabe-se, contudo, que eram parteiras, enfermeiras e assistentes, conhecedoras das ervas medicinais. Exerciam papel de médicas - sem titularidade - para outras mulheres e pessoas pobres, e com isso ganharam grande reconhecimento social. $\mathrm{O}$ que não agradou à elite dominante.

[...] o fato dessas mulheres usarem seus conhecimentos para a cura de doenças e epidemias ocorridas em seus povoados, acabou despertando a ira da instituição médica masculina em ascensão, que viu na Inquisição um bom método de eliminar as suas concorrentes econômicas, aliando-se a ela. (ANGELIN, 2005, online).

Quando o "teocentrismo" decai nos séculos XV e XVI, dando lugar ao "antropocentrismo", a Igreja Católica viu seu poder instável e descentralizado. A arte, a ciência e a filosofia estavam cada vez mais distantes da igreja. Para recuperar o centro das atenções, a Igreja Católica instaurou, então, os Tribunais da Inquisição, por meio das Cruzadas (ANGELIN, 2005). Deu-se início a uma campanha judicial realizada tanto pela Igreja Católica, como a Protestante e a elite dominante contra as mulheres da população rural.

Porém, as mulheres não poderiam ser mortas até confessarem seu "pacto com o demônio". Para acelerar o processo de confissão do crime, vários tipos de tortura foram utilizados, tais como: raspar os pelos de todo o corpo em busca de "marcas do diabo", que 
podiam ser verrugas ou sardas; perfuração da língua; imersão em água quente; perfuração do corpo da vítima com agulhas; surras violentas; estupros com objetos cortantes; decapitação dos seios e, "[...] quem sustentava sua inocência, acabava sendo queimada viva. Já as que confessavam, tinham uma morte mais misericordiosa: eram estranguladas antes de serem queimadas" (ANGELIN, 2005, online).

Somente no século XVIII se deu o fim da caça às bruxas, embora o Tribunal da Inquisição tenha durado até o início do século XX. Para Angelin (2005), o que houve foi um verdadeiro genocídio de mulheres, com a intenção de conter qualquer avanço delas e aniquilar seu poder na sociedade.

A chegada do Iluminismo no século XVIII foi o movimento cultural e intelectual basilar da Revolução Francesa, promovendo a burguesia, quando, enfim, cessou o regime absolutista; sucedeu assim o primórdio da instauração do capitalismo - sistema socioeconômico onde os meios de produção e o capital, são propriedade privada. Com o fim do absolutismo, veio à ruína também o poder dos senhores feudais, e acreditava-se que, no novo modelo de estado, os homens (em geral) abririam mão do seu poder sobre as mulheres. Surgiu daí a primeira movimentação de mulheres junto aos homens, que pediam por direito ao voto - dentre várias outras pautas, esta, porém, era vista como a mais importante. Contudo, o fortalecimento das instituições democráticas - tais como direitos de propriedade, direitos contratuais, educação pública - acabavam por excluir cada vez mais a participação das mulheres. Andrea Nye explica que:

\footnotetext{
Sem os direitos de propriedade que substituíram o título de posse feudal, sem a capacidade de integrar as relações contratuais que tomaram o lugar das responsabilidades e direitos feudais, sem acesso à educação que permitia aos homens competir, sem acesso ao mercado de trabalho que assegurava à mão-de-obra qualificada e aos trabalhadores braçais a obtenção de empregos, a situação das mulheres na sociedade capitalista dificilmente era melhor do que havia sido no feudalismo (1995, p. 22).
}

O crescimento do trabalho assalariado fora de casa, realizado por homens, terminou por desvalorizar ainda mais o trabalho doméstico. As revoluções burguesas nada representaram em conquistas para as mulheres; apesar da desvalorização do trabalho doméstico, mesmo as que trabalhavam em escala industrial sofriam com salário menor e condições insalubres de trabalho.

Enquanto isso, em Genebra em 1866, a “[...] Association Internationale des Travailleurs condenou o trabalho das mulheres como uma degeneração da raça, afirmando 
que o lugar da mulher é em casa, como mãe e zeladora do lar para os homens [...]” (NYE, 1995, p. 54) e, na mesma época, "Em 1877 o Congresso Sindical na Inglaterra aprovou uma resolução em que o lugar da mulher era no lar e que o trabalho do homem deveria sustentá-lo" (NYE, 1995, p. 54).

Diante desse cenário, nasce no Reino Unido um movimento de mulheres burguesas que acreditavam ser capazes de assumir postos de relevada importância na sociedade e votar por isso. Nasce em 1897, o movimento pelo sufrágio feminino que, inicialmente, aliás, era pacífico. Foi Emma Goldman (Estados Unidos) quem alertou para a conversão do voto em "fetiche", juntamente com Clara Zetkin (Alemanha) e Alexandra Kollontai (Rússia), porque, como explica Andrea Nye:

\footnotetext{
As mulheres, quer votem ou não, aceitam o que as escraviza: a religião, o lar, a guerra. [...] $\mathrm{O}$ voto se transformara num novo ídolo para as mulheres adorarem do mesmo modo como adoram deuses masculinos. [...] Não apoiariam a mudança no direito de família, liberdade sexual, separação da igreja e Estado ou partidos políticos. Pelo contrário, teriam apoiado causas humanitárias não-ameaçadoras [...]. (1995, p. 60).
}

Ademais, só há exatos cem anos, na revolução Russa, que deu origem à União Soviética em 1917, as mulheres tiveram seus direitos conquistados. Sob o governo de Lênin, pressionado por Kollontai, criou-se a Secretaria de Mulheres do Estado Socialista da Rússia, que tinha como função proteger os direitos tomados pelas mulheres no início do século, tais como, conforme Nye (1995): licença maternidade, centros de assistência à infância, divórcio para mulheres e homens; pautas que, como defendia Kollontai, só eram possíveis no socialismo.

\section{Enquanto isso no Brasil...}

No Brasil, em 1889, Clóvis Beviláqua era convidado para escrever o Código Civil Brasileiro, que só em 1916 foi aprovado, entrando em vigor em 1917. Servido dos moldes patriarcais, o Código foi considerado por Maria Berenice Dias, no texto A mulher no Código Civil, de 2010, como consolidador da superioridade masculina, transformando a força física do homem em poder pessoal, o que lhe garantia poder sobre a família.

Logo no início da Lei $\mathrm{n}^{\circ} 3.071$ de 1916 , o artigo $6^{\circ}$ estabelecia que, ao contrair matrimônio, a mulher perderia sua capacidade para certos atos; deveria ser assistida pelo 
marido e seu domicílio passaria a ser o dele (CC/16, art. 36, parágrafo único); até o sobrenome do esposo era obrigada a acrescentar ao seu (CC/16, art. 240). Sem autorização do marido, a mulher casada não podia exercer profissão, não podia alienar ou gravar de ônus real os imóveis de seu domínio particular, qualquer que fosse o regime de bens e litigar em juízo civil e comercial (CC/16, art. 242, II, VI e VII) (RODRIGUES; ARAÚJO, 2016).

\begin{abstract}
Um dos artigos mais misóginos envolvia o culto à preservação do corpo feminino a virgindade -, fortemente sustentado pelo cristianismo durante o patriarcado brasileiro. $\mathrm{O}$ defloramento da mulher configurava erro essencial sobre a pessoa. $\mathrm{O}$ homem, não conhecendo o fato ou "defeito" poderia pedir a anulação do casamento (CC/16, art. 219, IV). O prazo para pedir a anulação do matrimônio com uma mulher já deflorada prescrevia em dez dias, contados da sua realização $(\mathrm{CC} / 16$, art. $\left.178, \S 1^{\circ}\right)$. Importante ressaltar que, a preservação da virgindade feminina significava a honra do pai e do marido e, ainda hoje, persiste como regra em diversas instituições religiosas (RODRIGUES; ARAÚJO, 2016, p. 284).
\end{abstract}

Ademais, o casamento era indissolúvel. Sendo permitido o desquite - leia-se não quites, ou seja, contraia-se um débito com a sociedade - que apenas rompia a sociedade conjugal, mas não dissolvia o casamento (DIAS, 2010).

Dentre as regras machistas, de cunho religioso, o dever conjugal de fidelidade (CC/16, art. 231, I) trazia em seu bojo a responsabilidade recíproca, embora a realidade mostrasse outro sistema. A mulher acaba sendo alvo da norma e do controle; e para o homem, a obrigatoriedade simplesmente desaparece. Desse modo, a esposa infiel perdia todos os seus direitos para o cônjuge (CC/16, art. 231); une-se a isso o direito de guarda dos filhos menores (CC/16, art. 326); tão pouco poderia casar-se com o cúmplice da infidelidade (CC/16 art. 193, VII), sendo obrigada a retirar o nome do cônjuge (CC/16, art. 324) e, ainda, não poderia exigir pensão alimentícia (CC/16, art. 320). (RODRIGUES; ARAÚJO, 2016). Embora, como sustenta Beauvoir (1970), para o homem a poligamia sempre foi mais ou menos abertamente tolerada.

Mais adiante, em 1942, entrava em vigor o Decreto-lei $\mathrm{n}^{\circ} 2.848$, de 7 de dezembro de 1940, mais conhecido como Código Penal Brasileiro, escrito e revisto pelos legisladores penais Alcântara Machado, Nelson Hungria, Vieira Braga, Macélio de Queiroz e Roberto Lira. O momento era propício, aliás, visto que o país passava por um processo de transformação sociocultural.

Não obstante, em todo o mundo as mulheres organizavam-se novamente para dar mais um salto na busca dos seus direitos. Nos anos 1950 as mulheres começaram a questionar 
a maternidade, bem como exigir métodos contraceptivos e, outra vez em pauta, a legalização do aborto. Esses ideais de liberdade sexual há tanto tempo - e de tantas formas - almejados pelas mulheres, chegaram ao Brasil, e as mulheres não precisavam mais contrair matrimônio ou sair de casa para se sustentarem. Evidentemente, Estado e Igreja acharam-se intimamente tocados com esse novo panorama que surgia; ambos sustentados pela égide do instituto do casamento, quando a mulher não se vê mais na obrigação de cumpri-la, apelaram então para outro instituto, também em seu poder: a legislação.

Em forma de Código Penal, regado pelo sistema patriarcal, o legislador consegue tomar controle sobre o corpo da mulher, da maneira que o Código Civil não fez. Por exemplo, no capítulo denominado "Dos crimes contra o costume", o legislador divide a mulher, sob um juízo de valor embasado pelo machismo, em "honesta" e "desonesta". Mulher "honesta" como sendo a casada - obediente e fiel; se solteira, a virgem. Tornando todas as outras mulheres como "desonestas" e, portanto, merecedoras do crime, por exemplo, de estupro.

Sustentam Carla Estela Rodrigues e Eronides Araújo que “[...] o teor do dispositivo dizia: ter conjunção carnal com uma mulher "honesta", mediante fraude; pena de reclusão; de um a três anos (CP/40, art. 215, I)" (2016, p. 288). Defendendo, inclusive, o marido contra acusação do crime de estupro, visto que lhe era permitido exigir, pelas vias do matrimônio, que a esposa tivesse conjunção carnal com ele, “[...] dessa forma, para os doutrinadores mais antigos, 'o marido que constrangesse a esposa, mediante violência ou grave ameaça, a ter com ele relação sexual, estaria acobertado pela excludente de ilicitude do exercício regular de seu direito" (NUCCI apud RODRIGUES; ARAÚJO, 2016, p. 288).

Percebe-se que o ideal machista, alicerçado pelo modelo patriarcal de sociedade, condena de toda forma a mulher, a fim de mantê-la casta, pura e virgem, controlada pelo poder masculino. Para isso, o legislador não poupou esforços, tutelando, inclusive, sobre o direito feminino ao aborto, visto que, apesar de ser um crime que condena mulheres, foram poucas as prisões ocasionadas no país. O dispositivo no Código Penal tornou-se simbólico, porém assertivo quanto às dominações masculinas sobre o corpo da mulher, condenando, inclusive socialmente, a mulher que recusa a maternidade (RODRIGUES; ARAÚJO, 2016).

É importante salientar que, assim como defendem Rodrigues e Araújo:

O Código Civil de 1916 vigorou até o ano de 2002 e, serviu como um instrumento para reforçar a subversão da mulher ao homem, o caráter reprodutivo do sexo feminino, bem como os papéis predeterminados que orientavam o comportamento da mulher, razão pela qual, quatorze anos após a revogação do Código, precisamos ainda discutir as desigualdades de gêneros que permeiam a sociedade brasileira do século XXI (2016, p. 292). 
Mister ainda ressaltar que também as leis penais, respaldadas pelas leis civis, mantinham um juízo de valor arraigado de machismo, em sua maioria, até 2005. Era comum, dessa forma, nos anos 1990, o marido ser "perdoado" juridicamente, facilmente amparado pelo dispositivo legal do adultério, por exemplo, que considerava crime contra o casamento a infidelidade. Assim, se o homem agredisse ou assassinasse “[...] a esposa, ex-esposa, namorada ou ex-namorada, infiel ou não, tinha uma saída fácil para livrar-se da prisão: alegar a tese da 'legítima defesa da honra” (RODRIGUES; ARAÚJO, 2016, p. 292).

Existe uma comunhão masculina na sociedade que subjuga a mulher, ordenada por um sistema criterioso, porém moldável no tempo e no espaço, que permite que o homem, independente do espaço e do tempo, exerça o papel inverso ao da mulher, o de poder.

À medida em que a sociedade evolui em tecnologias e meios de produção, o patriarcado encontrava meios para se afirmar, seja pelo pai, ou depois com o casamento, pelo marido. Agora é respaldado pelas leis, que proíbem as mulheres de decidir sobre escolhas que dizem respeito a sua própria vida. Como defendem Rodrigues e Araújo, "O fenômeno das leis, por sua vez, estimulou e estimula a ideologia androcêntrica, fazendo parte de todo o processo de formação ou 'deformação' de consciência política na sociedade” (2016, p. 293).

A deformação chegou a tal ponto que a mulher passa a ser atacada por todos os aspectos da vida em sociedade: o papel delas na família torna-se secundário; os meios de comunicação de massa passam a explorá-la; até as roupas femininas são usadas como um esquema masculino de oprimir e objetificar mulheres, sustentados pela legitimidade que tem o Estado para intervir em escolhas, evidentemente individuais, em prol de uma "moral" coletiva. E, como bem sustenta Nye, "Você pode indagar dos efeitos de certas representações ideológicas, mas já não há qualquer padrão para avaliar sua progressividade. No final todos os julgamentos devem basear-se na perspectiva política de cada um”. (1995, p. 82).

Mesmo com o advento da Constituição Federal de 1988, que enfatizou a igualdade entre homens e mulheres, bem como seus direitos e obrigações (inc. I do artigo $5^{\circ}$ ), não houve alteração na legislação infraconstitucional que, mesmo sem eficácia legislativa, continuava no ordenamento jurídico. O Código Civil mantinha, no texto legal, dispositivos que distinguiam direitos do marido (artigos 233 a 239) e da mulher (artigos 240 a 255). Assim como os dispositivos: "[...] art. 233 - o marido é o chefe da sociedade conjugal, função que exerce com a colaboração da mulher (...). Compete-lhe: inc. I - a representação legal da família; inc. II - a administração dos bens comuns e dos particulares da mulher (...); inc. III - 
o direito de fixar o domicílio da família (...); inc. IV - prover a manutenção da família (...)" (DIAS, 2010, online).

As novas estruturas familiares, como a monoparental, reconhecida pela Constituição de 1988, não foram regulamentadas pelo Código Civil. Como salienta Dias, "Tal omissão prejudica o universo de $32 \%$ das famílias brasileiras que são chefiadas por mulheres" (2010, online). Infere-se disso que "A história tradicional e oficial do Brasil é uma história das elites políticas, do homem branco, das classes dominantes [...], onde os pobres, negros e índios são somente coadjuvantes eventuais, e as mulheres (sem distinção de raça ou classe social) simplesmente não existem" (COSTA, 1998, p. 91).

Ainda que vários sejam os direitos alcançados, a mulher ainda é preterida nos diversos aspectos, públicos e privados, da vida em sociedade. Não obstante, dados tirados do site de observatório de gênero do Governo Federal nos mostram que “[...] o Brasil apresenta um dos maiores níveis de disparidade salarial. No país, os homens ganham aproximadamente 30\% a mais que as mulheres de mesma idade e nível de instrução" (OBSERVATÓRIO, 2009, online), ainda que ocupem o mesmo cargo. O trabalho doméstico é ainda majoritariamente (92\%) ocupado por mulheres - e $62 \%$ por mulheres negras - sendo assalariado ou não. Trabalho este que sempre ocupou espaço e tempo na vida das mulheres, preterindo-as no que se refere à educação, lazer, cultura, política, etc, como visto anteriormente.

Se vislumbrarmos, por exemplo, que a garantia de direitos se dá por meio de legislação favorável, a representação das mulheres na política hoje é, indiscutivelmente, menor que a dos homens. Tendo em vista a representação no parlamento brasileiro, onde 13\% das cadeiras são ocupadas por mulheres em contraste a $87 \%$ das cadeiras ocupadas por homens em exercício no Congresso Nacional (ESTADÃO, 2015). Dados que nos permitem constatar que, na política, as demandas das mulheres dificilmente serão sanadas.

A violência contra a mulher, contudo, ainda figura como a forma de opressão mais forte e resistente no tempo, tanto na esfera pública como na privada, visto que faz vítimas fatais, e quando não é fatal, deixa marcas na vida das mulheres. Importante salientar que, mesmo com as diversas leis específicas para mulheres no tocante à violência física, existe um número alarmante de feminicídios ${ }^{6}$ (anteriormente conhecido como "crime passional") e estupros - tipos penais estes que serão explicados posteriormente.

\footnotetext{
6 Termo usado para designar crimes de ódio por motivo de gênero - definido como crime doloso contra mulheres. Tal crime, tipificado pela Lei $\mathrm{n}^{\mathrm{o}} 13.104 / 15$, alterou o Código Penal (vigente), adicionando no rol do parágrafo $2^{\circ}$, do artigo 121 , dos crimes qualificados, o inciso VI, que seja o feminicídio.
} 
Depreende-se disso que, ainda que a legislação tenha suprido algumas demandas sobre os direitos da mulher (obviamente impulsionada pela pressão feminista), o aparato jurídico demonstra insuficiência na aniquilação das opressões que as mulheres sofrem. Diante dessa conjuntura, mister observar que a ação dos movimentos feministas como precursores de uma educação voltada para garantia dos direitos da mulher e empoderamento feminino é salutar para a sobrevivência das mulheres na sociedade. Em relação a isso, expressa o Relatório da Comissão Parlamentar Mista de Inquérito - CPMI da Violência contra a Mulher que:

\begin{abstract}
As diversas formas de violência - como a praticada no âmbito doméstico por parceiros íntimos ou familiares, a violência sexual, o tráfico de mulheres, a violência institucional, a violência contra mulheres com deficiência, a violência decorrente do racismo, a lesbofobia e o seximo - e o feminicídio são violações aos direitos humanos das mulheres, incompatíveis com o Estado Democrático de Direito e com o avanço da cidadania, em boa parte patrocinado pelas conquistas do movimento feminista e de mulheres nos últimos séculos (2013, p.7).
\end{abstract}

Há, contudo, uma forte oposição da sociedade em geral ao movimento feminista, grande parte gerada pela indiferença e ignorância sobre o assunto. Mas não só por isso, visto que sempre que os homens têm seu poder ameaçado, encontram meios de reafirmá-lo, como já foi demonstrado pelo resgate histórico feito neste trabalho. E encontram meios porque sempre foi, e ainda é protegido por todos os institutos que regem a sociedade.

É, no entanto, na educação pela teoria feminista e com o empoderamento pela prática da mesma, que a mulher - principalmente a marginalizada pela pobreza e pelo racismo - reconhece e passa a lutar por seu lugar de fala e de ação. Individualmente, porém, é impossível vencer as barreiras impostas pelo patriarcado.

Só com a união e organização das demandas a mulher empoderada tomará posse sobre tudo o que diz respeito à sua própria vida, bem como emancipar-se - economicamente, emocionalmente, fisicamente - não só a si mesma, mas todas as outras. Essa emancipação se dará, dentre várias formas, tanto com mais representantes na política, quanto por meio de ações dos governos, e com as mobilizações dos movimentos sociais.

\title{
Feminismo e Direito: a faca e o queijo
}


Por feminismo, como dito anteriormente, entendemos ser um movimento que, dentre suas múltiplas origens e objetivos, promove a igualdade entre mulheres e homens (MARIANO, 2016, online). A partir desse entendimento, temos que o movimento alavancado por Bertha Lutz - bióloga formada na França e bacharel em direito formada no Rio de Janeiro - foi o primeiro a organizar feministas no Brasil, em 1918, e teve como principal escopo o sufrágio feminino pela nominada Liga pela Emancipação Intelectual da Mulher.

Doutora em Literatura Brasileira pela USP, a professora Constância Lima Duarte escreve em seu artigo, denominado Feminismo e Literatura no Brasil, sobre as ondas do feminismo no Brasil, em 2003. Com o que se infere de Cecília Santos, trataremos do termo "onda", como o movimento que "[...] expressa o fluxo e o refluxo dos movimentos feministas em constante transformação no correr das águas misturadas entre o passado e o futuro [...]" (2008, p. 2). Além disso, cabe explicar que esta denominação é usada neste trabalho, exclusivamente, para ilustrar melhor a (ao) leitora (r) sobre os diferentes momentos em que o feminismo se associou à conquista dos direitos da mulher. Sabe-se, contudo, que, em termos gerais, essa diferenciação é feita para ilustrar o feminismo na sua vertente liberal, fazendo parecer que as mulheres tenham parado de lutar em determinados momentos da história. Estas autoras entendem o contrário, e como a exemplo das feministas socialistas - onde as mulheres já tinham vários direitos, como aborto, por exemplo, na Rússia Soviética, os quais as liberais só levantariam bandeira anos mais tarde - entendemos que as mulheres sempre estiveram em luta.

Sobre a primeira onda, que tem início nas primeiras décadas do século XIX, Constância Duarte salienta que "Urgia levantar a primeira bandeira, que não podia ser outra senão o direito básico de aprender a ler e a escrever (então reservado ao sexo masculino)" (2003, online). As primeiras - e poucas - escolas que aceitaram ensinar mulheres conventos, casas de corte e costura, bem como de boas maneiras e gastronomia -, eram consideravelmente tendenciosas, o que nos permite entender porque há tão poucos registros de mulheres e sobre mulheres na história, mesmo quando já podiam ler e escrever.

No artigo, a autora destaca que as primeiras mulheres a terem uma educação diferenciada cuidaram de emancipar outras mulheres, como é o caso de Nísia Floresta Brasileira Augusta, natural do Rio Grande do Norte. Aos vinte e dois anos, escreveu seu primeiro livro, intitulado Direitos das mulheres e a Injustiça dos homens, em 1832. Apesar da tenra idade, Nísia Floresta registrou em seu livro a insatisfação com a educação voltada aos serviços domésticos e, subversivamente, "[...] ridiculariza a ideia dominante da superioridade masculina [...]" (DUARTE, 2003, online). 
A segunda onda do feminismo, que começou no final do século XIX, somente teve sucesso no Brasil em 1934, quando da Constituinte que prestigiou o sufrágio feminino, tema da Liga pela Emancipação Intelectual da Mulher, que anos mais tarde se tornou Federação Brasileira pelo Progresso Feminino - dirigida por Bertha Lutz, em 1922. A luta incorporou inflamados discursos e manifestos nacionais quando, em 1927, o então governador do Rio Grande do Norte, Juvenal Lamartine, aprovou lei estadual que permitia o voto às mulheres do estado (DUARTE, 2003).

Com início nos anos 1970, a terceira onda vem sob a denominação de "revolução sexual". Tal época ensejou os primeiros métodos contraceptivos e, para Duarte, foi o momento "[...] que foi capaz de alterar radicalmente os costumes e tornar as reivindicações mais ousadas em algo normal [...]" (2003, online). No Brasil, a conjuntura histórica e política do momento, no contexto da ditadura militar, exigiu das mulheres maior esforço à luta e a outras lutas sobre outras causas, como a luta contra a censura, pela redemocratização do país, e por melhores condições de vida (DUARTE, 2003, online).

A violência contra a mulher acabou por se tornar bandeira de luta que agrega todas as mulheres em suas diferentes etnias, classes sociais e orientação sexual. Assim, no começo da década de 1980, nasce, em diversas partes do país, a SOS Mulher (hoje extinta), que oferecia assistência social, psicológica e jurídica para as mulheres em situação de violência doméstica. Cecília Santos salienta que a maioria das mulheres que procuravam essa assistência, além de denunciar a violência conjugal, "Queixavam-se também da humilhação que elas sofriam ao tentar prestar queixas nas delegacias de polícia, lotadas predominantemente por policiais do sexo masculino" (2008, p. 6).

Atendendo a essas reivindicações, o poder executivo permite a criação das Delegacias Especializadas em Atendimento à Mulher - DEAM, inicialmente denominadas de Delegacia de Defesa da Mulher - DDM, em meados de 1980, como medida protetiva às mulheres em situação de violência doméstica e familiar, visto que se acreditava que a solução estava na criminalização. Nesse processo, o então presidente do país, José Sarney, aprova, por meio das pressões dos movimentos feministas, a criação do Conselho Nacional dos Direitos da Mulher - CNDM, em 1985, que fomentou o lobby feminista - conhecido como "[...] 'lobby do batom', o qual conseguiu incluir $80 \%$ das reivindicações feministas na nova Constituição de 1988" (SANTOS, 2008, p. 7). As reivindicações exigiam, dentre outras coisas, 
[...] 1) maior politização da violência contra mulheres, coordenação de campanhas educacionais e conscientização das mulheres sobre o problema; 2) criação de casas abrigo e de novas instituições para fornecer atendimento jurídico e psicológico às vítimas da violência doméstica e sexual; 3) mudanças nas instituições jurídicas e policiais, como a capacitação dos policiais numa perspectiva anti-machista, bem como a contratação de assistentes sociais em cada delegacia de polícia; 4) reformulação da legislação machista; 5) fomento de pesquisas sobre violência contra mulheres; e 6) incorporação das preocupações dos movimentos de mulheres na agenda das políticas públicas (SANTOS, 2008, p. 8).

Contudo, tais demandas não foram sanadas, e dentre as que foram, tiveram atenção precária, fazendo com que as DEAM's ainda constituam principal meio de política pública para enfrentamento à violência contra a mulher. Atualmente o país conta com 368 delegacias em todo território nacional, segundo dados da Secretaria Especial de Políticas para Mulheres $-\mathrm{SPM}^{7}$.

A Secretaria Especial de Política para as Mulheres foi criada através da medida provisória 103 de 2003, e representa principal meio de aprovação das leis que criaram mecanismos amplos para coibir, punir e prevenir a violência contra a mulher, introduzindo a violência doméstica e familiar contra a mulher no ordenamento jurídico brasileiro. Na opinião de Cecília Santos, “A articulação deste órgão com as organizações não-governamentais feministas em todo o país possibilitou uma pressão bem sucedida no governo Lula e no Congresso Nacional" (2008, p. 23). Tanto que a Lei $\mathrm{n}^{\mathrm{o}} 10.886$, de 2004, alterou o texto do Código Penal, inserindo o crime "violência doméstica", sob pena de detenção de seis meses a um ano; e em 2006, é aprovada a Lei Maria da Penha, que amplia os mecanismos de proteção e prevenção em relação à violência doméstica e familiar contra a mulher (SANTOS, 2008).

Para melhor entendimento desse processo, voltando um pouco no resgate histórico, temos que em 1996, o Brasil promulga a Convenção Interamericana para Prevenir, Punir e Erradicar a Violência Contra a Mulher (concluída em Belém-PA, no ano de 1994). Entendendo que o estado deve dar uma atenção diferenciada à proteção da mulher, dispõe o primeiro artigo da Convenção que "[...] entender-se-á por violência contra a mulher qualquer ato ou conduta baseada no gênero, que cause morte, dano ou sofrimento físico, sexual ou psicológico à mulher, tanto na esfera pública como na esfera privada" (CIDH, 1996, online).

Na sequência, em 1998, Maria da Penha Maia Fernandes - biofarmacêutica formada - faz a primeira denúncia da violência doméstica que sofria do seu marido, o professor Marco Antonio Viveiros, para a Comissão Interamericana de Direitos Humanos.

\footnotetext{
${ }^{7}$ Secretaria Especial de Política para Mulheres. Disponível em: $<$ https://sistema3.planalto.gov.br/spmu/atendimento/atendimento_mulher.php?uf=TD $>$. Acesso em: 24 abr. 2017.
} 
Sendo que a primeira violência que sofreu por parte do marido ocorreu em 1983, quando aquele a deixou paraplégica; na segunda agressão, ele a empurrou da cadeira de rodas e tentou eletrocutá-la no chuveiro. A partir daí, foram vinte anos de luta na justiça para ver seu agressor preso ${ }^{8}$.

Após enviar o processo à Comissão Interamericana de Direitos Humanos (OEA) a qual pela primeira vez recebe denúncia de violência doméstica -, Maria da Penha consegue a prisão de seu agressor em 2002. Além disso, a "[...] OEA também condenou o Brasil por negligência e omissão em relação à violência doméstica" (UFBA, 2017, online) e, como punição, sugeriu a criação de lei específica para violência doméstica e familiar, dentre outras coisas.

Foi então que se criou a Lei $\mathrm{n}^{\mathrm{o}}$ 11.640, que entrou em vigor em 2006, popularmente conhecida como Lei Maria da Penha, a qual discorre sobre a violência sexual, física e psicológica, e ainda acrescenta a violência patrimonial e moral no rol de violências contra a mulher. Dessa forma, a violência contra a mulher passa a ser tratada como de maior potencial ofensivo, eliminando as penas pagas em cestas básicas e as multas. Para aprovação dessa Lei, o estado sofreu fortes pressões dos movimentos feministas. Além disso, a violência contra a mulher, quando atendida em serviços de saúde pública ou privada, será objeto de notificação compulsória, em todo território nacional, como cumprimento à Lei $\mathrm{n}^{\mathrm{o}}$ 10.778 , de 2003 .

Mesmo com a promulgação da Lei Maria da Penha, ainda se verificam alarmantes números de assassinatos de mulheres no país. O Mapa da Violência 2015 - elaborado pela Faculdade Latino-Americana de Ciências Sociais, ONU mulheres, Organização PanAmericana da Saúde/Organização Mundial da Saúde e Secretaria de Política para as Mulheres - contabilizou, em 2013, um número de 4,8 assassinatos em cada 100.000 mulheres no país, o que coloca o Brasil em $5^{\circ}$ lugar no ranking de países em relação a esse tipo de crime ${ }^{9}$; tais assassinatos representam, pois, aproximadamente 13 homicídios femininos diários em 2013 (Mapa da Violência, 2015).

Além do caso de Maria da Penha, Cecília Santos atenta para outro caso que também foi encaminhado para a Comissão Interamericana de Direitos Humanos: “[...] o caso Márcia Leopoldi, que se refere ao assassinato de Leopoldi por seu ex-namorado, tendo sido

\footnotetext{
${ }^{8}$ Tirado do site de Observatório da Lei Maria da Penha da UFBA. Disponível em:

$<$ http://www.observe.ufba.br/lei_mariadapenha>. Acesso em: 24 abr. 2017.

${ }^{9}$ Mapa da Violência 2015: Homicídio de Mulheres no Brasil. Disponível em:

$<$ http://www.agenciapatriciagalvao.org.br/dossie/pesquisas/mapa-da-violencia-2015-homicidio-de-mulheres-nobrasil-flacsoopas-omsonu-mulheresspm-2015/>. Acesso em 24 abr. 2017.
} 
encaminhado à CIDH em 1996 [...]” (2008, p. 24). Analisando-se a batalha dos dois casos em ganhar visibilidade pelo governo federal - os quais foram atendidos sob uma lentidão injustificável -, percebe-se que o país necessitava (e ainda necessita) de uma reformulação de todo o sistema de justiça criminal, uma vez que as delegacias não supriam certas expectativas, evidenciando total descaso do estado brasileiro com a dignidade humana da mulher.

Concomitante a este cenário, com o advento da teoria feminista, e com a prática desta, surgiu no Brasil, nas décadas de 1980 e 1990, a criminologia feminista como alternativa política-criminal - dentre as várias propostas no campo da criminologia crítica que surgiam ao sistema penal vigente à época. Na esfera de investigação sobre o sistema penal, a criminologia feminista “[...] permitiu ao 'malestream' criminológico compreender a lógica androcêntrica que define o funcionamento das estruturas de controle punitivo" (CAMPOS; CARVALHO, 2011, p. 152), lógica esta que define um conceito de segurança total e onipresente, mas que, em verdade, sequer contempla o âmbito privado e familiar, revelado nos dados de violência contra a mulher.

Nesse aspecto, a Lei Maria da Penha, que antes era prestigiada pelo Juizado Especial Cível e Criminal - JECRIM, determina a criação dos Juizados de Violência Doméstica e Familiar Contra a Mulher, “[...] a serem implantados nos tribunais de cada Estado" (SANTOS, 2008, p. 28), órgãos da Justiça Ordinária com competência civil e criminal, responsáveis pelo processo, julgamento e execução de demandas motivadas pelo uso da Lei. Infelizmente, o número de Juizados e Varas é demasiadamente pequeno, sendo contabilizados apenas 112 no país, diante da demanda exigida pela violência contra a mulher, sendo que 57 destas estão localizadas nas capitais e o restante nas cidades do interior (CNJ, 2017, online $)^{10}$ - embora, segundo o Mapa da Violência 2015, os mais altos índices de violência contra a mulher se encontram em municípios com população menor a 100 mil habitantes.

Sobre políticas públicas para mulheres, a SPM elaborou um relatório que esmiúça sobremaneira como se dá a criação e efetivação das políticas para mulheres, asseverando que "[...] é necessário que se estabeleça o sentido das mudanças que se pretende, sobretudo, com vistas a contemplar a condição emancipatória e a dimensão de autonomia das mulheres [...]" (2012, online). Declara ainda, no relatório, que a pressão do movimento feminista se torna imprescindível na batalha contra o patriarcado e o machismo politicamente institucional,

\footnotetext{
${ }^{10}$ Site do Conselho Nacional de Justiça - CNJ. Disponível em $<$ http://www.cnj.jus.br/noticias/cnj/84405juizados-de-violencia-domestica-ainda-sao-insuficientes>. Acesso em: 25 abr. 2017.
} 
apontando para "[...] a importância do ativismo político das mulheres organizadas para assegurar políticas públicas de gênero [...]”' (SPM, 2012, online).

Ademais, sabe-se que as Delegacias Especiais de Atendimento a Mulher padecem de um atendimento precário, uma vez que, até os dias atuais, conta com número pequeno de profissionais qualificados sobre o tema da violência doméstica; além disso, tais delegacias funcionam em horário comercial comum, ou seja, abrem às 8 horas da manhã e terminam seus serviços às 18 horas da tarde, não abrindo aos sábados e nem aos domingos. Sendo que, no relatório feito pela CPMI Violência contra a Mulher, consta que as agressões atingem seu ápice justamente após as 18 horas da tarde e nos finais de semana - quando o agressor se encontra no ambiente doméstico e familiar.

Incide atentar para esta falha gravíssima dos poderes (executivo, legislativo e judiciário) em todos os âmbitos (nacional, estadual e municipal), uma vez que, como já explicado, as DEAM's constituem principal política pública de enfrentamento à violência contra a mulher. $\mathrm{O}$ que revela a absoluta importância do movimento feminista continuar a pleitear essas lutas.

Contudo, a teoria feminista aponta para um problema ainda maior - não apenas em relação à violência contra a mulher -, que se consagra estrutural. Para Ana Alice Alcântara Costa (1998), a concepção liberal da cidadania não assimila todas as opressões às quais estão submetidas as mulheres, apontando que para elas, na prática, a condição de gênero oprimido, sua vulnerabilidade física (fruto do estereótipo feminino criado pelo patriarcado), a tripla jornada de trabalho (hoje entendida como a laboral, a doméstica e a maternal), obstaculizam o exercício da cidadania - isso, também, em todas as esferas da vida.

\section{CONSIDERAÇÕES FINAIS}

A história mostrou que, no mundo, a vontade masculina sempre prevaleceu; mais que isso, o homem detinha todos os poderes concretos. As mulheres eram mantidas em condição de subjugação; serviam não só para procriação, mas para sustentar o status quo do homem - o de dominação. Disso se verifica, por exemplo, que a divisão sexual do trabalho diferenças entre as atividades realizadas por mulheres e homens -, se materializa facilmente para o homem, uma vez que toda atividade realizada por mulheres tinha menor valor (no mercado e no lar), era secundária. 
A partir das lutas feministas, como vimos, a legislação tenta suprir as demandas que integrem especificamente as mulheres, elaborando, em seus textos, regras que coíbam e limitem os homens, e emancipem-nas. Ainda assim, há morosidade injustificável no atraso da garantia de direitos básicos como à vida, à participação na política, à cultura, à educação, à segurança integral, dentre outros direitos. Contudo, nada há de ser conquistado no individualismo - entendido aqui em modo amplo de conquista, onde se atinge primeiramente o coletivo, para tutelar o individual; pois, somente pela organização, as mulheres conseguiram exercer pressão, ao ponto de dar visibilidade às demandas exigidas e alcançar as mulheres da mais baixa camada da pirâmide de relações hierárquicas do sistema capitalista. É evidente que as pressões das feministas, organizadas e reunidas nos movimentos, operaram como molas propulsoras nas conquistas dos direitos das mulheres.

É mister entender que as demandas sanadas pelo judiciário, em relação à violência contra a mulher, ainda são meramente de cunho criminal, isto é, o enfrentamento a tal violência é restringido a uma questão de polícia. Apesar do reconhecimento do avanço, é de comum entendimento que as legislações não transformaram o conjunto das contradições sociais que revestem as relações sociais no contexto capitalista periférico, em que prioriza-se a condenação do agressor (quando ocorre) em detrimento de outras demandas que deveriam ser conjuntas e ainda requerem atenção, como: saúde (psicológica e emocional), assistência social, orientação jurídica, bem como uma educação sobre prevenção a essas violências, entre outras, pautas ainda caras ao movimento feminista.

É preciso que as mulheres se organizem incessantemente, até conquistarem tudo que lhes é de direito, e se mantenham na vigília, para que nenhum direito conquistado lhes seja tirado. Ademais, o judiciário brasileiro tem entendido - com base nas fortes pressões feministas - por atender as demandas das mulheres e suas especificidades (como a maternidade, por exemplo), que deveria lhes garantir posição que lhes é de direito, mas sempre lhes foi negada: a de ser humano!

\section{REFERÊNCIAS}

ANGELIN, Rosângela. A “caça às bruxas": uma interpretação feminista. Disponível em: $<$ https://www.espacoacademico.com.br/053/53angelin.htm>. Acesso em: 16 mar. 2017.

BEAUVOIR, Simone. O segundo sexo: fatos e mitos. 4. ed. São Paulo: Difusão Europeia do Livro, 1970. 
CAMPOS, Carmen Hein de; CARVALHO, Salo. Tensões atuais entre a criminologia feminista e a criminologia crítica: a experiência brasileira. In: CAMPOS, Carmen Hein de (Org.). Lei Maria da Penha comentada em uma perspectiva jurídico-feminista. Rio de Janeiro: Lumen Juris, 2011. p.143-172.

CNJ - CONSELHO NACIONAL DE JUSTIÇA. 2017. Disponível em $<$ http://www.cnj.jus.br/noticias/cnj/84405-juizados-de-violencia-domestica-ainda-saoinsuficientes $>$. Acesso em: 25 abr. 2017.

COSTA, Ana Alice Alcântara. As donas do poder: Mulher e Política na Bahia. Salvador: NEIM/UFBA; Assembleia Legislativa da Bahia, 1998.

CPMI - COMISSÃO PARLAMENTAR MISTA DE INQUÉRITO. Relatório da violência contra a mulher no Brasil. Brasília: Senado Federal, 2013.

DIAS, Maria Berenice. A mulher no Código Civil. 2010. Disponível em: < http://www.mariaberenice.com.br/manager/arq/(cod2_726)18_a_mulher_no_codigo_civil.pd f>. Acesso em: 16 mar. 2017.

DUARTE, Constância L. Feminismo e literatura no Brasil. 2003. Disponível em: < http://www.scielo.br/scielo.php?pid=S0103-40142003000300010\&script=sci_arttext $>$. Acesso em: 23 abr. 2017.

ENGELS, Friedrich. A origem da família, da propriedade privada e do estado. 9. ed. Rio de Janeiro: Civilização Brasileira, 1984.

ESTADÃO, O. Estado de São Paulo. 2015. Brasil tem menos mulheres no legislativo que Oriente Médio. Disponível em: < http://politica.estadao.com.br/noticias/geral,brasil-temmenos-mulheres-no-legislativo-que-oriente-medio,1645699>. Acesso em: 18 mar. 2017.

MARIANO, Fátima. 2016. O que é feminismo. Disponível em:

$<$ http://www.scielo.mec.pt/scielo.php?script=sci_arttext\&pid=S0874-68852016000100019>. Acesso em: 23 abr. 2017.

NYE, Andrea. A teoria feminista e as filosofias do homem. Trad. Nathanael C. Caixeiro. Rio de Janeiro: Rosa dos Tempos, 1995.

OBSERVATÓRIO DE GÊNERO. Homens recebem salários 30\% maiores que as mulheres no Brasil. 2009. Disponível em: <

http://www.observatoriodegenero.gov.br/menu/noticias/homens-recebem-salarios-30maiores-que-as-mulheres-no-brasil/> . Acesso em: 18 mar. 2017.

RODRIGUES, Carla Estela dos Santos; ARAÚJO, Eronides Câmara de. 2016. Leis Civis e Penais machistas do século XX e a obra homens traídos. Disponível em: < http://www.abarriguda.org.br/revista/index.php/revistaabarrigudaarepb/article/view/296>. Acesso em: 11 mar. 2017.

SAFFIOTI, Heleieth. Gênero, patriarcado e violência. São Paulo: Editora Fundação Perseu Abramo, 2004.

SARDENBERG, Cecilia M. B.; COSTA, Ana Alice A. Feminismos, feministas e movimentos sociais. Disponível em: $<\mathrm{https}$ ://books.google.com.br/books?hl=pt$\mathrm{BR} \& 1 \mathrm{r}=\& \mathrm{id}=\mathrm{SJ} \mathrm{rBzbfJARgC} \& \mathrm{oi}=\mathrm{fnd} \& \mathrm{pg}=\mathrm{PA} 81 \& \mathrm{dq}=$ feminismos + feministas $+\mathrm{e}+$ movimento

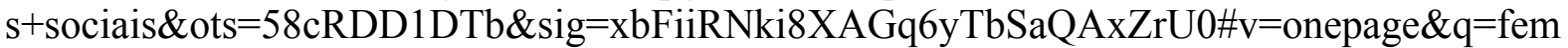
inismos $\% 20$ feministas $\% 20 \mathrm{e} \% 20$ movimentos\%20sociais\&f=false $>$. Acesso em: 16 mar. 2017. 
SANTOS, Cecília M. Da delegacia da mulher à Lei Maria da Penha: lutas feministas e políticas públicas sobre violência contra a mulher no Brasil. CES: Coimbra, Oficina $\mathrm{n}^{\circ} 301$, 2008 .

SPM-SECRETARIA ESPECIAL DE POLÍTICA PARA MULHERES. Políticas Públicas para Mulheres. 2012. Disponível em: < http://www.spm.gov.br/central-deconteudos/publicacoes/publicacoes/2012/politicas_publicas_mulheres $>$. Acesso em: 25 abr. 2017. 